\title{
S100B Protein in Urine of Preterm Newborns with Ominous Outcome
}

\author{
DIEGO GAZZOLO, PASQUALE FLORIO, SABINA CIOTTI, EMANUELA MARINONI, ROMOLO DI IORIO, \\ MATTEO BRUSCHETTINI, RENATA SACCHI, GIOVANNI SERRA, MARIO LITUANIA, \\ AND FABRIZIO MICHETTI
}

\begin{abstract}
Department of Pediatrics [D.G., S.C., M.B., R.S., G.S.], G. Gaslini Children's Hospital University of Genoa, Genoa I-16167, Italy; Department of Fetal, Maternal, and Neonatal Health [D.G.], G. Garibaldi Hospital, Catania I-95100, Italy; Department of Pediatrics, Obstetrics, and Reproductive Medicine [P.F.], University of Siena, Siena I-57100, Italy; Laboratory of Perinatal Medicine and Molecular Biology [E.M., R.D.], University "La Sapienza," Rome I-00168, Italy; Fetal and Perinatal Medicine Centre [M.L.], Galliera Hospital, Genoa I-16100, Italy; Institute of Anatomy and Cell Biology [F.M.], Catholic University, Rome I-00168, Italy
\end{abstract}

\begin{abstract}
Prematurity is an important cause of perinatal death, and no reliable biochemical/biophysical markers exist to identify newborns with an increased mortality risk. We aimed to use S100B concentrations in urine as an early indicator of risk of neonatal death. We did a cross-sectional study using urine obtained from 165 preterm newborns, of whom 11 suffered neonatal death within the first week, 121 displayed no overt neurologic syndrome, and 33 suffered neonatal hypoxia and intraventricular hemorrhage (IVH) but not ominous outcome. Urine S100B concentrations were determined at four time-points and corrected for gestational age by conversion to multiples of median (MoM) of healthy controls of the same gestational age. Ultrasound imaging was assessed within the first $72 \mathrm{~h}$ from birth. In infants that died within the first week, S100B levels in urine were already higher than controls at first urination and increased progressively between the 24 and 96-h time-points. Multiple
\end{abstract}

Prematurity constitutes the main cause leading to perinatal death and about 10-15\% of high-risk newborns might have an ominous outcome $(1,2)$. The possibility of early identification of infants at higher risk of death is to date limited, inasmuch as clinical, laboratory and standard monitoring procedures may be of no avail. There is thus a constant need for practical and sensitive markers able to identify patients at higher risk as early

Received January 3, 2005; accepted May 122005.

Correspondence: Diego Gazzolo, M.D., Ph.D., Department of Pediatrics, Giannina Gaslini Children's University Hospital, Via Guglielmo Oberdan 80/1, 16167 Genoa, Italy; e-mail: dgazzolo@hotmail.com

The present study was supported in part by grants provided to F.M. from the Italian Ministry of University, Research and Technology (F.I.R.B.); the "Sacro Cuore" Catholic University, Roma, Italy; and from the Italian Ministry of Health, and to D.G. from the National Research Council, the Italian Ministry of University, Research and Technology (COFIN 2001) and from the "Let's improve prenatal life" Foundation. The funding source had no role in the study design, in the collection, interpretation, or analysis of the data or in the writing of the report.

DOI: 10.1203/01.pdr.0000185131.22985.30 logistic regression analysis showed a significant correlation between urine S100B protein concentrations and the occurrence of neonatal death. An S100B concentration cut-off of $12.93 \mathrm{MoM}$ at first urination had a sensitivity of $100 \%$ and a specificity of $97.8 \%$ for predicting an ominous outcome. The positive predictive value was $78.6 \%$, the negative predictive value was $100 \%$. Measurement of urine S100B protein levels in preterm newborns could be useful to identify newborns at higher risk of neonatal death. (Pediatr Res 58: 1170-1174, 2005)
Abbreviations
IVH, intraventricular hemorrhage
MoM, multiples of median
NICUs, neonatal intensive care units
SNAP-PE, Score for Neonatal Acute Physiology-Perinatal
Extension

as possible, to take immediate preventive or therapeutic measures. The inclusion of such a marker in evidence-based guidelines is eagerly awaited; however, at present no effective biochemical or biophysical tools exist to predict newborns at higher risk of perinatal death (1-4).

The presence in blood of elevated concentrations of a brain constituent such as S100B protein has been described as prognostic of death in adults, and it has been suggested that measurement of this protein be included among peri-mortem procedures (5). $\mathrm{S} 100 \mathrm{~B}$ is an acidic calcium-binding protein of the EF-hand family (6) that is highly concentrated in the nervous system; it has a half-life of about $1 \mathrm{~h}$ and is mainly eliminated in urine (7). In this respect, raised urine $\mathrm{S} 100 \mathrm{~B}$ concentrations are a consolidated marker of brain damage in infants $(8-10)$ and in preterm newborns with IVH (11), whereas increased amniotic fluid S100B concentrations are a marker of fetal death (12). Because urine is a clinically accessible fluid for the measurement of S100B when monitoring newborns at high risk, we aimed to evaluate whether 
S100B concentrations in urine represent a useful method to identify preterm newborns at risk of postnatal death. At birth, we also evaluated clinical parameters, cerebral ultrasound patterns, and neonatal neurologic conditions.

\section{MATERIALS AND METHODS}

Patients. We did a cross-sectional study with urine obtained from preterm newborns ( $n=165 ; 27-32$ wk of gestation; mean $30 \pm 2 \mathrm{wk}$ ), whom we recruited consecutively between January 1, 1999, and May 31, 2003, at our tertiary referral centers for NICUs. For this study we enrolled as control subjects ( $n=154$; mean \pm SD gestational age: $30 \pm 2 \mathrm{wk})$ preterm infants in whom no overt neurologic syndrome was detectable $(n=121)$, and preterm newborns $(n=33)$ who suffered neonatal hypoxia and IVH but not ominous outcome. We diagnosed IVH at $72 \mathrm{~h}$ from birth by standard cerebral ultrasound scanning (13), which we performed using a real-time ultrasound machine (Acuson 128SP5, Mountain View, CA).

Case subjects $(n=11$; mean \pm SD gestational age: $30 \pm 2 \mathrm{wk})$ were infants who died within the first week after birth. All cases had a normal karyotype and the fetuses had no detectable anomalies; fetuses with malformations or congenital heart disease and women exposed to alcohol or tobacco smoke were excluded from the study.

We obtained informed consent from the mothers of all newborns before inclusion in the study, as well as approval from our local human investigation committee.

The severity of illness in the first $24 \mathrm{~h}$ after birth was measured using the SNAP-PE (14). In addition, on admission to the NICU we routinely assessed the clinical parameters of all newborns [red blood cells count (RBCs), venous blood $\mathrm{pH}$, ion concentrations, plasma glucose levels], and performed a daily neurologic examination [according to Prechtl (15)].

Emergency cesarean section was performed in 6 of the 11 cases in the neonatal death group and in 77 out of 154 cases in the control group. Indications included placental abruption and nonreassuring fetal status, as defined by the American College of Obstetricians and Gynecologists [bradycardia, fetal heart rate) FHR late decelerations, severe and repetitive FHR variable decelerations, reduced beat-to-beat variability] (16). We administered corticosteroid therapy (betamethasone, $12 \mathrm{mg} / 24 \mathrm{~h}$ for two days i.v., Bentelan, Glaxo Wellcome, Verona, Italy) in 6 of the 11 cases in the neonatal death group and in 85 out of 154 cases in the control group; and tocolytic therapy (Ritodrine $30-50 \mathrm{mg} / \mathrm{h}$ i.v., Miolene, Lusofarmaco, Milan, Italy) in 3 out of 11 women whose newborns died within the first week, and in 37 of the 154 women whose newborns were included in the control group.

S100B measurement. We measured S100B protein levels in urine at first urination (time 0), and 24 (time 1), 48 (time 2) and 96 (time 3) h after birth. We collected urine samples at each time-point, immediately centrifuged them at $900 \mathrm{~g}$ for $10 \mathrm{~min}$, and stored the supernatants at $-70^{\circ} \mathrm{C}$. We measured $\mathrm{S} 100 \mathrm{~B}$ in urine with a commercially available immunoluminometric assay (Lia-mat Sangtec 100, AB Sangtec Medical, Bromma, Sweden), and we performed the measurements in duplicate according to the manufacturer's instructions: the averages are reported. This assay is specific for the $\beta$ subunit of the S100 protein and measures the $\beta$ subunit using three MAb (SMST 12, SMSK 25 and SMSK 28). The $\beta$ subunit of the S100 protein is known to be predominant $(80-96 \%)$ in the human brain $(8,17)$.

The assay detection limit was $0.02 \mu \mathrm{g} / \mathrm{L}$ : precision was less than $5.5 \%$ for intra-assay and less than $10.1 \%$ for inter-assay.

Statistical analysis. We expressed the results of S100B concentrations in urine as mean [lower and upper 95\% confidence interval (CI)] and assessed differences between groups by the Mann Whitney $U$ test. We performed multiple logistic regression analysis with the occurrence of neonatal death as the dependent variable, to analyze the influence of various clinical parameters [delivery mode, gestational age, tocolytic therapy, antenatal maternal glucocorticoids administration, chorioamnionitis, incidence of respiratory distress syndrome (RDS), neurologic examination, the occurrence of IVH, S100B urine levels, SNAP-PE score] on the occurrence of neonatal death.

Because amounts of S100B in urine correlate with gestational age $(8,18)$, we corrected concentrations for gestational age by conversion to MoM of the controls of the same gestational age. We stratified controls by gestational age, and the medians of each stratum were used to convert all values into MoM. We matched cases with control medians according to gestational age at the time of urine sampling. We divided $\mathrm{S} 100 \mathrm{~B}(\mu \mathrm{g} / \mathrm{L})$ concentrations by the median values of control groups of the same gestation period to improve statistical power and allow external validation of results from different populations, besides allowing regression analysis of data to reach a day-by-day estimate of the expected normal S100B concentrations (19).

We used the cut-off indicated by ROC curve analysis $(19,20)$ to evaluate the positive and negative predictive values, specificity and sensitivity, and likeli- hood ratios with their respective $95 \%$ confidence bounds. Thus, we estimated the probability of neonatal death in preterm newborns and compared it with the pretest probability, defined as the prevalence of neonatal death in the whole group of patients (21).

Statistical analysis was performed using the GraphPad Prism version 3.00 for Windows (GraphPad Software, Inc., San Diego, CA). A value of $p<0.05$ was considered significant.

\section{RESULTS}

Clinical findings and neonatal outcomes of all the infants studied are shown in Table 1. We did not find significant differences regarding gestational age and weight at birth, delivery mode, gender, age at admission to NICUs, antenatal maternal glucocorticoid treatment, tocolytic therapy, the incidence of chorioamnionitis and of emergency cesarean section, and Apgar scores $<7$ at 1 and $5 \min (p>0.05$ for all). Furthermore, laboratory parameters such as RBC count, hemoglobin, hematocrit rate, venous blood $\mathrm{pH}$, venous carbon dioxide and oxygen partial pressure, base excess, urea, creatinine, and urine gravity did not differ between the two study groups ( $p>0.05$ for all).

The incidence of RDS, the need for mechanical ventilation support, the number of infants treated with surfactant and inotrope drugs was significantly $(p<0.001)$ higher in the preterm infants with ominous outcome, whereas no significant difference was found for the occurrence of symptomatic patent ductus arteriosus $(p>0.05)$.

The incidences of normal and suspect neurologic examination patterns, assessed at admission to NICUs were, respectively, significantly $(p<0.05)$ lower and significantly $(p<0.01)$ higher in the neonatal death group. No significant $(p>0.05)$ difference between the two groups was observed regarding abnormal neurologic patterns. Neurologic abnormalities assessed in 35 preterm infants included hypertonia/hypotonia syndrome (neonatal death group: $n=2$; controls: $n=27$ ) and hyperexcitability ( $n=6$ in controls). Isolated symptoms were present in 12 preterm infants, including hypertonia-hypotonia (neonatal death group: $n=2$; controls: $n=2$ ), dystonia (controls: $n=3$ ) and hyperexcitability (neonatal death group: $n=1$; controls: $n=4$ ) (Table 1). The same incidences of normal and suspect neurologic examination patterns were observed at 24, 48, and $96 \mathrm{~h}$ after birth and did not differ with respect to admission time point being, respectively, significantly $(p<0.05)$ lower and significantly $(p<0.01)$ higher in the neonatal death group. However, no significant differences $(p$ $>0.05)$ regarding neurologic abnormalities have been shown between groups.

Cerebral ultrasound patterns evaluated at $72 \mathrm{~h}$ after birth showed a significantly $(p<0.01)$ higher incidence of IVH in newborns with ominous outcome (neonatal death group: 45\%; controls: $21 \%$, respectively). Ultrasound IVH patterns in the 38 preterm infants included 23 grade-II IVH (neonatal death group: $n=3$; controls: $n=20$ ) and 15 grade-III IVH (neonatal death group: $n=2$; controls: $n=13$ ). No other ultrasound abnormalities were described at this monitoring time-point.

SNAP-PE scores measured in the first $24 \mathrm{~h}$ after birth showed significantly $(p<0.05)$ higher values in preterm infants with ominous outcome (Table 1). According to the occurrence of IVH, as diagnosed by cerebral ultrasound, preterm control infants were subdivided into control group A (without IVH: $n=121$ ) and control group B (with IVH: $n=$ 33). SNAP-PE values were significantly $(p<0.001)$ higher in 
Table 1. Perinatal data in neonatal death and control groups (mean $\pm S D$ )

\begin{tabular}{|c|c|c|}
\hline & Neonatal death $(n=11)$ & Controls $(n=154)$ \\
\hline \multicolumn{3}{|l|}{ Perinatal clinical characteristics } \\
\hline Birth weight $(\mathrm{g})$ & $1297 \pm 392$ & $1441 \pm 287$ \\
\hline Gestational age (wk) & $33.1 \pm 2.08$ & $32.6 \pm 2.24$ \\
\hline Age at study entry (h) & $3 \pm 1$ & $3 \pm 1$ \\
\hline Born at study hospital, no. (\%) & $7(64)$ & $101(66)$ \\
\hline Antenatal glucocorticoid therapy, no. (\%) & $6(54)$ & $85(55)$ \\
\hline Caesarean Section, no. (\%) & $6(54)$ & $77(51)$ \\
\hline \multicolumn{3}{|l|}{ Factors associated with primary outcomes } \\
\hline \multicolumn{3}{|l|}{ Apgar score, no. (\%) } \\
\hline At $1 \min <7$ & $6(54)$ & $81(52)$ \\
\hline At $5 \min <7$ & $2(18)$ & $27(17)$ \\
\hline RDS, no. (\%) & $8(72)^{*}$ & $58(34)$ \\
\hline \multicolumn{3}{|l|}{ Neurological examination, no. $(\%)$} \\
\hline Normal Suspect & $6(55)$ & $112(73)$ \\
\hline Suspect & $3(27) *$ & $9(6)$ \\
\hline Abnormal & $2(18)$ & $33(21)$ \\
\hline SNAP-PE score in the first $24 \mathrm{~h}$ from birth & $59.7 \pm 5.4^{*}$ & $49.9 \pm 8.9$ \\
\hline
\end{tabular}

$* p<0.05$ vs controls.

control group B than control group A, whereas no significant ( $p$ $>0.05$ ) difference was found between control group B and the neonatal death group. Furthermore, SNAP-PE values in the neonatal death group were significantly $(p<0.01)$ higher than in the control group A.

In the neonatal death group, 5 out of the 11 died within the first $96 \mathrm{~h}$ (mean, $91 \mathrm{~h}$ ) from birth and the remaining 6 cases died within the first week (mean, $114 \mathrm{~h}$ ) due to cardiopulmonary failure (Table 1). Detailed postmortem examination indicated, among different causes of neonatal death, the presence of IVH grade IV (IVH and signs of periventricular leukomalacia) $(n=5)$, multiorgan failure, including CNS patterns suggestive of severe perinatal hypoxia ( $n=3$ ), and cardiopulmonary failure with CNS signs of severe hypoxia $(n=3)$. No neuronal migrational anomaly was detected in the 11 cases examined.

Urine S100B protein levels were detectable in all cases examined ( $n=165)$. In particular, S100B levels were significantly higher at all monitoring time-points $(p<0.001)$ in infants who later died. Urine levels of S100B were significantly higher than controls at first urination $(p<0.001)$ and increased progressively between the 24- and 96-h time-points ( $p<0.001$ for all) (Table 2). Urine levels of S100B were significantly $(p<0.001)$ higher in preterm infants with ominous outcome than in both control groups A and B. Furthermore, $\mathrm{S} 100 \mathrm{~B}$ levels in group B were significantly $(p<0.001)$ higher than in group A (Table 2).

Multiple forward regression analysis with neonatal death as the dependent variable showed a positive significant $[p<0.001$; odds ratio (OR), 9.55, respectively] correlation only between urine S100B levels, measured at birth, and the occurrence of neonatal death among a series of monitoring parameters.

The sensitivity/specificity, positive/negative predictive values, likelihood ratios, and the area under the curve (AUC) of $\mathrm{S} 100 \mathrm{~B}$ protein as a diagnostic test, evaluated by the ROC curve, at different monitoring time-points are shown in Table 3. As can be seen, the higher S100B values as diagnostic test were observed at first urination; at the cut-off of $12.93 \mathrm{MoM}$ S100B achieved a sensitivity of $100 \%\left(\mathrm{CI}_{95 \%}: 71.3-100\right)$ and a specificity of $97.8 \%\left(\mathrm{CI}_{95 \%}: 93.8-99.5\right)$ as a single marker for the prediction of neonatal death (Fig. 1). The ROC AUC of $\mathrm{S} 100 \mathrm{~B}$ was 0.995 . In contrast, SNAP-PE scores at the cut-off of 51 combined a sensitivity of $100 \%\left(\mathrm{CI}_{95 \%}: 71.3-100\right)$ with a specificity of $48.9 \%\left(\mathrm{CI}_{95 \%}: 40.4-57.5\right)$ for prediction of neonatal death. The ROC AUC of SNAP-PE score was 0.715 , and

Table 2. Urine SIOOB concentrations (MoM) expressed as mean (lower and upper 95\% CI), measured at first urination (0), and at 24 (1), 48 (2), 96 (3) $h$ in neonatal death and control groups A (without IVH) and B (with IVH)

\begin{tabular}{|c|c|c|c|c|c|c|c|c|c|}
\hline S100B MoM & \multicolumn{3}{|c|}{ Neonatal death group $(n=11)$} & \multicolumn{3}{|c|}{ Control group A $(n=121)$} & \multicolumn{3}{|c|}{ Control group B $(n=33)$} \\
\hline First urination $(0)^{* \neq}$ & 20.31 & 13.41 & 33.02 & 0.67 & 0.10 & 2.00 & 9.53 & 1.70 & 15.56 \\
\hline $48 \mathrm{~h}(2)^{*} \neq$ & 59.37 & 21.00 & 113.70 & 0.92 & 0.12 & 3.79 & 25.54 & 1.30 & 68.00 \\
\hline $96 \mathrm{~h}(3)^{* *}$ & 81.08 & 21.98 & 219.80 & 0.89 & 0.14 & 2.66 & 33.11 & 1.17 & 96.51 \\
\hline
\end{tabular}

$* p<0.001$ vs control group A.

$\ddagger p<0.01$ vs control group $\mathrm{B}$. 
Table 3. Sensitivity, specificity, and predictive values of serial urinary S100B levels as diagnostic test for early neonatal death prediction

\begin{tabular}{lcccccrrr}
\hline $\begin{array}{c}\text { Monitoring } \\
\text { time-point }\end{array}$ & $\begin{array}{c}\text { S100B (MoM) } \\
\text { cut-off value }\end{array}$ & Sens (\%) & Spec (\%) & PPV (\%) & NPV (\%) & LR (+) & LR (-) & AUC \\
\hline First urination & 12.93 & 100 & 97.8 & 78.6 & 100 & 46.3 & 0.0 \\
24 h (1) & 15.86 & 100 & 90.9 & 40 & 99 & 0.995 \\
48 h (2) & 38.00 & 90.9 & 94.8 & 62.5 & 99.1 & 17.6 & 0.1 \\
96 h (3) & 10.00 & 100 & 85.3 & 36.7 & 100 & 0.938 & 0.967 \\
\hline
\end{tabular}

PPV, positive predictive value; NPV, negative predictive value; Sens, sensitivity; Spec, specificity; LR, positive (+) and negative (-) likelihood ratio; AUC, area under the curve.

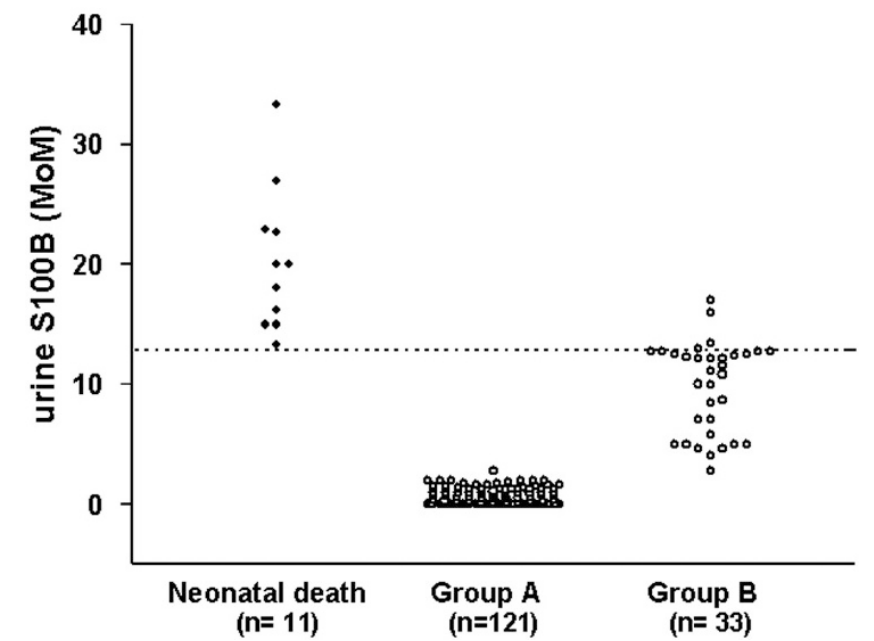

Figure 1. S100B levels in urine at first urination. S100B concentrations were significantly ( $p<0.001$ ) higher in newborns who died within the first week $(\bullet)$ ( $n=11)$ than in healthy controls $(n=154)$ (o; Group A: without IVH, $n=$ 121; Group B: with IVH, $n=33)(p<0.001)$. ROC curve analysis shows that the S100B measurement as a diagnostic test has a sensitivity and a specificity of $100 \%$ and $97.8 \%$, respectively, at a cut-off of 12.93 MoM (dashed line), with $78.6 \%$ positive predictive value and $100 \%$ negative predictive value.

was significantly lower than that of S100B $(p<0.001$; difference between areas: $0.280 ; \mathrm{CI}_{95 \%}$ : $0.104-0.455$, as evaluated by pair-wise comparison of ROC curves).

Eleven out of 165 newborns died after birth, giving an overall prevalence of neonatal death in the study population of $6.6 \%$ $\left(\mathrm{CI}_{95 \%}\right.$ : 0-55.2\%). This was the predicted probability of developing an ominous outcome before urine S100B measurement and SNAP-PE computation were performed (pretest probability). If at first urination $\mathrm{S} 100 \mathrm{~B}$ levels were found to be high (i.e. above the thresholds defined by the ROC curve analysis), the probability of neonatal death (positive predictive value) was as high as $78.6 \%$ $\left(\mathrm{CI}_{95 \%}\right.$ : 57-100), but if $\mathrm{S} 100 \mathrm{~B}$ concentrations were normal the probability of neonatal death was as low as $0 \%\left(\mathrm{CI}_{95 \%}\right.$ : $\left.0-2 \%\right)$. In contrast, the probability of predicting neonatal death by a high SNAP-PE score was $13 \%\left(\mathrm{CI}_{95 \%}: 6-13\right)$, whereas the probability was $0 \%\left(\mathrm{CI}_{95 \%}: 0-3.5\right)$ for a SNAP-PE score below the thresholds identified through ROC curve analysis. Finally, the probability of an ominous outcome in the presence of both S100B and SNAP-PE above the thresholds defined by the ROC curve analysis was superimposable on that of $\mathrm{S} 100 \mathrm{~B}$ as a single marker, but higher than that of the SNAP-PE score.

\section{DISCUSSION}

This is the first study to show that concentration of S100B, a marker of stress in the CNS in adults (4), newborns, and during gestation $(8-12,22)$ in the urine of infants who died in the first week after birth, is greatly increased. Furthermore, multiple logistic regression analysis showed that urine S100B concentration measured at birth was the only parameter that correlated with the occurrence of neonatal death. Because S100B is highly concentrated in the nervous system, and because it is released by kidney tissue (23), we postulate that the pathologic processes that cause neonatal death lead to increased protein concentrations in urine. The significance of such an increased concentration of urinary S100B warrants consideration. Data on elevated S100B concentrations in growth-retarded fetuses (24), in high-risk newborns developing hypoxic-ischemic encephalopathy $(8-10)$, and in the urine of newborns developing IVH (11) support the hypothesis that early severe hypoxia may be responsible for a continuous release of $\mathrm{S} 100 \mathrm{~B}$ protein from the damaged CNS into the systemic circulation and, finally, the urine. Thus, elevated S100B urine levels can represent an antenatal insult, which is known to account for $70 \%$ of cases of perinatal mortality and morbidity (3). This could be a direct consequence of brain cell damage, or of alteration in cell membrane permeability or blood/brain barrier permeability. However, it is also interesting that at nanomolar concentrations S100B stimulates neurite outgrowth and enhances survival of neurons during development (25), whereas micromolar levels of extracellular S100B in vitro stimulate the expression of proinflammatory cytokines and induce apoptosis $(26,27)$. In addition, cell-based and clinical studies have implicated S100B in the initiation and maintenance of a pathologic, glial-mediated proinflammatory state in the CNS (27). Animal studies have indicated that overexpression of S100B increases vulnerability to cerebral hypoxicischemic injury, as S100B transgenic mice subjected to hypoxia-ischemia showed a significant increase in mortality, more extensive cerebral injury and neuroinflammation in response to injury (28). Therefore, the possibility that some of the S100B measured in the urine of these patients derives from this process and participates in the pathologic cascade of events responsible for neonatal death should also be taken into account. In other words, perinatal hypoxia may trigger the secretion of S100B from the brain, which, in turn, when released in excess, participates in the cascade of events leading to death.

The hypothesis that hypoxia may contribute to the release of S100B into urine is supported by previous studies describing elevated S100B levels in fetuses and newborns that experienced perinatal asphyxia $(8,22,24)$ and by the fact that in our study preterm infants with ominous outcome had higher SNAP-PE values, and SNAP-PE is well known to include also parameters suggestive of severe hypoxia insult hypothesis as well as the occurrence of cerebral hemorrhage (14). 
However, the possibility that S100B may be released, at least in part, from other sites in which it is concentrated, such as adipose tissue (29) could also be considered. Unfortunately, data on the presence of the protein in adipocytes at this stage of maturity are not available. Likewise, at this stage data are lacking on the possible presence of S100B in the kidneys, which in any case do not appear to be a site of concentration for the protein (23). With respect to a possible placental origin, which should also be taken into consideration, given that the expression of the protein in human placenta has been reported (30), this source seems to be quantitatively not relevant, due to the limited half-life of the protein (about $1 \mathrm{~h}$ ) (6).

The second result of the present study concerns the possibility of early detection, by means of S100B measurements in urine in the perinatal period, of cases at higher risk of ominous outcome. Increased concentrations of S100B in amniotic fluid have been reported to be an early predictor of fetal death (12), and raised urine S100B concentrations are a consolidated marker of brain damage in preterm newborns with IVH (11). The increased release into the urine of a brain constituent such as S100B may offer a direct indicator of active cell damage at a stage when standard diagnostic procedures are still silent or of no avail. These findings may be relevant, bearing in mind that clinical, laboratory, and ultrasound patterns were unable to detect cases at risk of ominous outcome at a time when S100B concentrations in urine were already high, and that the quantification of S100B in the urine is rapid (about $1 \mathrm{~h}$ ), inexpensive, simple, and can be performed automatically. In addition, urine appears the most suitable among biologic fluids clinically/noninvasively accessible for the measurement of analytes, because it can be collected easily and sampling can be repeated without risk for the newborn, offering improved care of critical newborns, bearing in mind that anemia due to repeated blood sampling is a common pathology in high-risk newborns (31).

As shown by ROC curve analysis, the probability of death within the first week was as high as $78.6 \%$ in newborns with urinary S100B levels higher than $12.93 \mathrm{MoM}$, so that early detection of increased levels of S100B might also represent a warning of the danger of neonatal death. Furthermore, the S100B cut-off specificity and sensitivity, predictive values, likelihood ratios and AUC with their respective 95\% confidence bounds were significantly more accurate than other clinical tools for neonatal surveillance, such as SNAP, SNAPPE, and CRIB $(14,32)$.

In conclusion, the measurement of $\mathrm{S} 100 \mathrm{~B}$ in urine may provide physicians with an additional clinical tool for detecting high-risk preterm newborns at an earlier stage. Whether the increased release of S100B is a causal factor or reflects an adaptive phenomenon warrants further investigations.

Acknowledgments. The authors thank Sangtec Medical, Bromma, Sweden, and Byk Gulden Italia for supplying analysis kits.

\section{REFERENCES}

1. US Department of Health and Human Services 1991 Perinatal Mortality, Sec 3. Vital Statistics of the United States, 1988, Vol II, Part A. Hyattsville, MD: US Department of Health and Human Services
2. McIntire DD, Bloom SL, Casey BM, Leveno KJ 1999 Birth weight in relation to morbidity and mortality among newborn infants. N Engl J Med 340:1234-1238

3. Hagberg B, Hagberg G, Beckung E, Uvebrant P 2001 Changing panorama of cerebral palsy in Sweden. VIII. Prevalence and origin in the birth year period 1991-1994. Acta Paediatr 90:271-277

4. Rennie JM, South M, Morley CJ 1987 Cerebral blood flow velocity variability in infants receiving assisted ventilation. Arch Dis Child 62:1247-1251

5. Petzold A, Green AJ, Keir G, Fairley S, Kitchen N, Smith M, Thompson EJ 2002 Role of serum S100B as an early predictor of high intracranial pressure and mortality in brain injury: a pilot study. Crit Care Med 30:2705-2710

6. Heizmann CW $1999 \mathrm{Ca}^{2+}$-binding S100 proteins in the central nervous system. Neurochem Res 24: 1097-1100

7. Jonsson H, Johnsson P, Hoglund P, Alling C, Blomquist S 2000 Elimination of S100B and renal function after cardiac surgery. J Cardiothorac Vasc Anesth 14:698-701

8. Michetti F, Gazzolo D 2002 S100B protein in biological fluids: a tool for perinatal medicine. Clin Chem 48: 2097-3004

9. Gazzolo D, Marinoni E, Di Iorio R, Bruschettini M, Kornacka M, Lituania M, Majewska U, Serra G, Michetti F 2003 Measurement of urinary S100B protein concentrations for the early identification of brain damage in asphyxiated full-term infants. Arch Pediatr Adolesc Med 157:1163-1168

10. Gazzolo D, Marinoni E, Di Iorio R, Bruschettini M, Kornacka M, Lituania M, Majewska U, Serra G, Michetti F 2004 Urinary S100B protein measurements: a tool for the early identification of hypoxic-ischemic encephalopathy in asphyxiated fullterm infants. Crit Care Med 32:131-136

11. Gazzolo D, Bruschettini M, Lituania M, Serra G, Bonacci W, Michetti F 2001 Increased urinary S100B protein as an early indicator of intraventricular hemorrhage in preterm infants: correlation with the grade of hemorrhage. Clin Chem 47:18361838

12. Florio P, Michetti F, Bruschettini M, Lituania M, Bruschettini P, Severi FM, Petraglia F, Gazzolo D 2004 Amniotic fluid S100B protein in mid-gestation and intrauterine fetal death. Lancet 364:270-272

13. Papile LA, Burstein J, Burstein R, Koffler H 1978 Incidence and evolution of subependymal and intraventricular hemorrhage: a study of infants with birth weights less than 1,500 gm. J Pediatr 92:529-34

14. Richardson DK, Phibbs CS, Gray JE, McCormick MC, Workman-Daniels K, Goldmann DA 1993 Birth weight and illness severity: independent predictors of neonatal mortality. Pediatrics 91:969-975

15. Prechtl HFR 1982 Assessment methods for the newborn infant: a critical evaluation In: Stratton P (ed) Psychobiology of Human Newborn. Wiley, Chichester pp 21-52

16. ACOG committee opinion: inappropriate use of the terms fetal distress and birth asphyxia 1998 Int J Gynecol Obstet 61:309-310

17. Jensen R, Marshak DR, Anderson C, Lukas TJ, Watterson DM 1985 Characterization of human brain S100 protein fraction: amino acid sequence of S100 beta. J Neurochem 45:700-705

18. Gazzolo D, Bruschettini M, Lituania M, Serra G, Gandullia E, Michetti F 2001 S100B protein concentrations in urine are correlated with gestational age in healthy preterm and term newborns. Clin Chem 47:1132-1133

19. Stephan C, Wesseling S, Schink T, Jung K 2003 Comparison of eight computer programs for receiver-operating characteristic analysis. Clin Chem 49:433-439

20. Zweig MH, Campbell G 1993 Receiver-operating characteristic (ROC) plots: a fundamental evaluation tool in clinical medicine. Clin Chem 39:561-577

21. Richardson WS, Wilson MC, Guyatt GH, Cook DJ, Nishikawa J 1999 Users' guides to the medical literature: XV. How to use an article about disease probability for differential diagnosis. Evidence-Based Medicine Working Group. JAMA 281:1214 1219

22. Nagdyman N, Komen W, Ko HK, Muller C, Obladen M 2001 Early biochemical indicators of hypoxic-ischemic encephalopathy after birth asphyxia. Pediatr Res 49:502-506

23. Haimoto H, Hosoda S, Kato K 1987 Differential distribution of immunoreactive S100-alpha and S100-beta proteins in normal nonnervous human tissues. Lab Invest 57:489-498

24. Gazzolo D, Marinoni E, di Iorio R, Lituania M, Bruschettini PL, Michetti F 2002 Circulating S100beta protein is increased in intrauterine growth-retarded fetuses. Pediatr Res 51:215-219

25. Haglid KG, Yang Q, Hamberger A, Bergman S, Widerberg A, Danielsen N 1997 S100beta stimulates neurite outgrowth in the rat sciatic nerve grafted with acellular muscle transplants. Brain Res 753:196-201

26. Hu J, Ferreira A, Van Eldik LJ 1997 S100beta induces neuronal cell death through nitric oxide release from astrocytes. J Neurochem 69:2294-2301

27. Rothermundt M, Peters M, Prehn JH, Arolt V 2003 S100B in brain damage and neurodegeneration. Microsc Res Tech 60:614-632

28. Wainwright MS, Craft JM, Griffin WS, Marks A, Pineda J, Padgett KR, Van Eldik LJ 2004 Increased susceptibility of S100B transgenic mice to perinatal hypoxiaischemia. Ann Neurol 56:61-67

29. Michetti F, Dell'Anna E, Tiberio G, Cocchia D 1983 Immunochemical and immunocytochemical study of S-100 protein in rat adipocytes. Brain Res 262:352-356

30. Marinoni E, Di Iorio R, Gazzolo D, Lucchini C, Michetti F, Corvino V, Cosmi EV 2002 Ontogenic localization and distribution of S-100beta protein in human placental tissues. Obstet Gynecol 99:1093-1099

31. Strauss RG 1995 Neonatal anemia: pathophysiology and treatment. Immunol Invest 24:341-351

32. Richardson DK, Corcoran JD, Escobar GJ, Lee SK 2001 SNAP-II and SNAPPEII: simplified newborn illness severity and mortality risk scores. J Pediatr 138:92-100 